\title{
Improved Quine-McCluskey's Method: An Easier Alternate Method for Simplifying Logic Expressions using Existing QMCC Method
}

\author{
Abhishek Chandrakant Gidde \\ Computer Science Department, \\ Dr. D. Y. Patil School of Engineering Academy \\ Pune, India
}

\begin{abstract}
This method was derived out of curiosity and simplifies the Qunie-McCluskey's algorithm further for faster simplification process. This method reduces the time required and complexity of reducing logic expressions to simpler forms.
\end{abstract}

\section{Keywords}

Improved QMcC, Quine-McCluskey's Algorithm, Simpler Calculations, Logic Expressions, Electronic

\section{INTRODUCTION}

The Quine McCluskey's (QMcC) Method in digital electronics is used for simplifying the logic expressions. QMcC method is chosen over all other as this method can easily be implemented on both pen and paper and even on computer systems. In our research we derived a new approach to the traditional algorithm which indeed reduced the time required for making pair and quad groups and also this method is a very fast approach to the QMcC's Method.

\section{THE TRADITIONAL METHOD}

A. Making Groups

\section{Step 1: (Group Formation)}

The first step is to group the min-terms depending upon the number of 1's in it's binary.

For example, if $\mathbf{Y}=\{\mathbf{1}, \mathbf{2}, \mathbf{3}, \mathbf{4 , 6 , 7 , 8 , 9 , 1 3}\}$

\begin{tabular}{|c|c|c|}
\hline Group 0 & $1,2,4,8$ & $\begin{array}{c}\text { Single '1' in } \\
\text { binary. }\end{array}$ \\
\hline Group 1 & $3,9,6$ & $\begin{array}{c}\text { Two '1's in } \\
\text { binary. }\end{array}$ \\
\hline Group 2 & 13,7 & $\begin{array}{c}\text { Three '1's in } \\
\text { binary. }\end{array}$ \\
\hline
\end{tabular}

$$
\begin{aligned}
& \text { Binary for } 1 \text { is }(0001)_{2} \\
& \text { Binary for } 3 \text { is }(0011)_{2} \\
& \text { Binary for } 13 \text { is }(1101)_{2}
\end{aligned}
$$

\section{Step 2: (Pair Formation)}

Now the second step is formation of Group of pairs from the last set of groups.

Here, according to the traditional method we will now form a new table for representing the groups of pairs.

\section{Traditional Method for Pair Formation:}

1. Start by comparing each term's binary from group 0

\author{
Janvi Vijaykumar Saddi \\ Computer Science Department,
}

Dr. D. Y. Patil School of Engineering Academy

Pune, India

with other groups.

2. Only if the binary of the two terms selected differs by a single bit then and only then the pair can be formed.

i.e. If we are comparing the two terms 2 (from Group 0 ) and 9 (from Group 1).

Binary of $9 \Rightarrow(1001)_{2}$

Binary of $2=>(0010)_{2}$

These two cannot form pairs as the there are three differed bit .

i.e. Bit 0 for 9 is 1 and for 2 its 0 .

Bit 1 for 9 is 0 and for 2 its 1 .

Bit 3 for 9 is 1 and for 2 its 0 .

Likewise, the two terms 2 and 6 can form a pair as the binary for 2 is $(0010)_{2}$ and the binary for 6 is $(0110)_{2}$ since they differ only in one bit that is the bit 3 .

3. Now for writing the binary representation of the pair we follow the below table:

(This step depends on the initial table of binaries where we group the binary numbers according to the number of 1's .)

\begin{tabular}{|c|c|c|}
\hline $\begin{array}{c}\text { Binary bit of } \\
\text { Group A. } \\
\text { (Change from) }\end{array}$ & $\begin{array}{c}\text { Binary bit of } \\
\text { Group B. } \\
\text { (Change to) }\end{array}$ & $\begin{array}{c}\text { Binary bit of the } \\
\text { pair so formed. }\end{array}$ \\
\hline 1 & 1 & 1 \\
\hline 0 & 1 & $-($ dash $)$ \\
\hline 1 & 0 & 1 \\
\hline 0 & 0 & 0 \\
\hline
\end{tabular}

Example: The binary of the pair $(2,6)$ can be represented as follows:

Pair: $(2,6)$ Binary $=>(0-10)$

\section{Step 3: (Quad formation)}

Now after the Pairing has been done we form Group of four terms called a 'Quad'.

\section{Traditional Method for Quad Formation:}

The quads are fromed using the previous table of pairs we formed

B. 
The template is used to format your paper and style the text. All margins, column widths, line spaces, and text fonts are prescribed; please do not alter them. You may note peculiarities. For example, the head margin in this template measures proportionately more than is customary. This measurement and others are deliberate, using specifications that anticipate your paper as one part of the entire proceedings, and not as an independent document. Please do not revise any of the current designations.

\section{OUR DERIVED METHOD (IMPROVED QMCC)}

We derived a new method for formation of Pairs and Quads, in our method we focused on making the method easier for human calculations and also machine calculations by reducing various dependencies and calculations, we termed the new system as 'J.A.R QMcC Method'.

To demonstrate our method we will take the same example we solved using the traditional method.

$\mathrm{Y}=\{1,2,3,4,6,7,8,9,13\}$

\section{J.A.R QMcC Method:}

\section{Step 1: (Grouping)}

Form this table as usual. (differed by number of 1's)

\begin{tabular}{|c|c|c|}
\hline Group 0 & $1,2,4,8$ & $\begin{array}{c}\text { Single '1' in } \\
\text { binary. }\end{array}$ \\
\hline Group 1 & $3,9,6$ & $\begin{array}{c}\text { Two '1's in } \\
\text { binary. }\end{array}$ \\
\hline Group 2 & 13,7 & $\begin{array}{c}\text { Three '1's in } \\
\text { binary. }\end{array}$ \\
\hline
\end{tabular}

\section{Step 1: (Pair Formation)}

\section{J.A.R QMcC rules for pair formation:}

1. If the number is $y$ then pair would be $(\mathrm{Y}, \mathrm{Y}+\mathrm{X})$.

a. Here, $\mathrm{X}$ can only be a number from the series $1,2,4,8,16,32$, i.e. $2^{0}, 2^{1}, 2^{2}, 2^{3}, \ldots, 2^{\text {n }}$.

b. X should belong to a successive group of the group of which $\mathrm{Y}$ is a member.

c. $(\mathrm{Y}+\mathrm{X})$ should be present in the logical expression.

Example:

If we want to find a pair with the term 1 ,

Put $\mathrm{Y}=1$,

The possible pairs are:

$\left(1,1+2^{0}\right)=>(1,2)$ :

Invalid as 1 and 2 are in the same group.

$\left(1,1+2^{1}\right)=>(1,3)$

Valid as 3 is in the next group.

$\left(1,1+2^{2}\right)=>(1,5)$

Invalid as $\mathbf{5}$ does not belongs to any group.

$\left(1,1+2^{3}\right)=>(1,9)$

Valid as 9 is in the successive group from 1.

$$
\left(1,1+2^{4}\right)=>(1,17)
$$

and so on till $\left(1,1+2^{\mathrm{n}}\right)$

- $\quad$ Pairs Marked with * are invalid as they have the same number of 1's in their binary.

Let's check this for the formation of pair with 3 .

Put $\mathrm{Y}=3$,

The possible pairs are:

$\left(3,3+2^{0}\right)=>(3,4)$

Invalid, as 4 is not in a successive group.

$\left(3,3+2^{1}\right)=>(3,5)$

Invalid, as 5 does belongs to any group.

$\left(3,3+2^{2}\right)=>(3,7)$

and so on till $\left(3,3+2^{\mathrm{n}}\right)$ given that 3 and $3+2^{\mathrm{n}}$ should not have same number of 1 's.

\section{Writing the binary of the pairs :}

The binary of these pairs can be written simple by these steps:

Consider the pair to be (A, B).

1. Write the binary of B.

2. Substitute 1 with "-" at position $P$.

Here, $\mathrm{P}=(\mathrm{n}+1)$ positon

Where $\mathrm{n}=\log _{2}(\mathrm{~B}-\mathrm{A})$

e.g.

If the pair is $(1,3)$

Binary of 3 is (0011)

We calculate,

$\mathrm{P}=\mathrm{n}+1$

$\mathrm{n}=\log _{2}(3-1)=\log _{2}(2)$

$\mathrm{P}=1+1=2^{\text {nd }}$ Position

We put '-' at $2^{\text {nd }}$ position.

So the binary for the pair is

$00-1$

\section{J.A.R Quad Formation:}

1. The pairs included in the Quad should belong to successive group of pairs.

2. If the pairs are $(\mathrm{A}, \mathrm{B})$ and $(\mathrm{C}, \mathrm{D})$ then the Quad can only be formed if:

a. $\mathrm{A}+\mathrm{D}=\mathrm{B}+\mathrm{C}$.

For Writing the Quad Binary:

1. Consider that the quad is (A,B,C,D).

2. Write the binary representation of $\mathrm{D}$, replacing ' 1 's with ''(dashes).

3. Now again put ' 1 ' in the binary at position $\mathrm{P}=\log _{2} \mathrm{~A}$.

e.g if the two pairs are $(1,3)$ and $(5,7)$

the quads can form a quad as:

$3+5=1+7$ 
So, the binary of 7 using '-" in place of '1's is 0 - - - i.e 0111

Now, put 1 again in position $\mathrm{P}=\log _{2}(1)=0^{\text {th }}$ position.

The so formed quad binary is 0 - - 1 .

C. Abbreviations and Acronyms

\begin{tabular}{|c|c|}
\hline Abbreviation & Meaning \\
\hline J.A.R QMCC & $\begin{array}{c}\text { Janvi and Abhishek's Reduced } \\
\text { Quine McClukseys Method. }\end{array}$ \\
\hline
\end{tabular}

\section{ACKNOWLEDGMENT}

We thank and appreciate the efforts of Miss. Shambhavi Sherur Ma'am for her efforts in teaching the concepts of digital electronics to us in a very effective and simple manner.

\section{REFERENCES}

[1] W.V Quine, "A Way to Simplify Truth Functions". The American Mathematical Monthly.

[2] E.J McCluskey, "Minimization of Boolean functions".

[3] R.P Jain, "Modern Electronics". 